\title{
Pathogenetically Grounded Approach to the Treatment of Children who Underwent Perinatal CNS Lesions
}

\author{
Olga N. Krasnorutskaya, PhD*; Vera S. Ledneva, PhD, ScD; Galina Golosnaya, PhD, ScD \\ Voronezh State Medical University named after N.N. Burdenko \\ Voronezh, the Russian Federation
}

\begin{abstract}
The aim of this study was to evaluate, based on the analysis of neurobiochemical markers, the effectiveness of pathogenetically substantiated therapy for disorders of the psychomotor and physical development of children in the first year of life who underwent perinatal hypoxia.

Materials and Methods: The study included 419 patients (52\% boys and 48\% girls) aged from 1 to 6 months. The main group included 336 patients in the first year of life who received inpatient treatment for perinatal CNS damage of different degrees of severity. The main group was divided into two subgroups according to age: Group $1(\mathrm{n}=163)$ between the ages of 1 and 3 months and Group $2(\mathrm{n}=173)$ between the ages of 4 and 6 months. In accordance with the severity of the CNS lesion, the main group was also divided into 3 subgroups: mild degree $(n=122)$, moderate degree $(n=118)$, and severe degree $(n=96)$. The control group included 83 apparently healthy children ( $n=43$ between the ages of 1 to 3 months and $n=40$ between the ages of 4 to 6 months). The analysis of individual physical development of the children was carried out using $\mathrm{Z}$ scores (weight, age, head circumference) and centiles ( 7 intervals ("corridors")) according to the WHO standard program WHO AnthroPlus, The concentrations of biochemical markers (L- Homocysteine, beta-NGF, S100 protein, angiotensin II) in the blood were evaluated in all children at admission, as a routine entry investigation. In accordance with a treatment regimen, the main group was also divided into 2 subgroups: subgroup A ( $\mathrm{n}=170)$, patients who received therapy depending on a general clinical manifestation; and subgroup B ( $\mathrm{n}=166)$, patients who received therapy depending on a dominant syndrome and variability of neurobiochemical markers.

Results: We found that Scheme B showed advantages for all studied neurobiochemical markers, with statistical significance for L-Hcy regardless of the age group. The positive dynamics were found in the ND severity against the background of Scheme $\mathrm{B}$ regardless of the age group and the degree of severity of the CNS lesion. Thus, the pronounced positive dynamics in the levels of neurotrophic and neurovascular markers of the CNS lesion in all age groups reflects the advantage of pathogenetic therapy. (International Journal of Biomedicine. 2018;8(3):192-196.)
\end{abstract}

Key Words: neurological deficit $\bullet$ nervous system $\bullet$ nerve growth factor $\bullet$ homocysteine

\section{Abbreviations}

AII, angiotensin II; Hcy, homocysteine; CNS, central nervous system; ND, neurological deficit; NGF, nerve growth factor; SOCG, Scale of the optimal course of gestation; SOCD, Scale of the optimal course of delivery.

\section{Introduction}

Despite the modern improvements in perinatal care with the introduction of various innovative treatment regimens for managing the revealed pathology in children during the first

*Corresponding author: Olga N. Krasnorutskaja, PhD Voronezh State Medical University named after N.N. Burdenko. Voronezh, Russia.E-mail: onkrasnorutckaja@rambler.ru year of life, severe consequences of perinatal CNS lesions still persist at a high frequency. ${ }^{(1-3)}$ According to the statistics of the Ministry of Health of Russia, since 2000 there has been more than a twofold increase in the rate of newborn encephalopathy, with perinatal hypoxia being the dominant factor in the formation of this pathology. ${ }^{(3,4)}$ According to the Russian Federal State Statistics Service, for the last five years in the Central Federal District, the proportion of children in the first year of life with an officially registered diagnosis 
"consequences of perinatal injury" has grown annually by an average of $0.6 \%$ (i.e. several thousand new patients who require a profile diagnosis, observation, and appropriate treatment, both in the medical organization and at home). There is a need for an effective early diagnosis system to optimize the treatment of children who underwent perinatal hypoxia, taking into account the complex analysis of neuromarkers of the CNS lesion. ${ }^{(5-8)}$ Modern standards for treatment of this condition are based on the syndromic approach, which is established during a neurological examination of the patient and, fundamentally, does not take into account the pathogenetic component in the development of a particular complex of neurological disorders. ${ }^{(9)}$

The microcirculatory insufficiency in childbirth and the antenatal period is the dominant link in the development of degenerative processes in CNS of newborns, which requires a more detailed analysis of the variability of neurovascular markers that reflect the formation of adaptation processes of the body. ${ }^{(3,5,10)}$ The capillary endothelium of the brain is extremely sensitive to ischemic-hypoxic effects, and its pathology occupies leading positions in the formation of neurological disorders. ${ }^{(5,7)}$ Homocysteine (Hcy) and angiotensin II (AII) are leading markers in the diagnosis of the pathomorphological state and function of the endothelium of the microcirculatory bed. They are released in high concentrations during damage to capillary structures, causing disruption of the passage of nerve impulses between neurons of the brain and myelination of the axonal structures of the white matter, that affects the metabolism of nerve cells and the regenerative potential of astrocytic glia, manifested by the variability in the blood levels of S100 protein and NGF.( $\left.{ }^{(}\right)$An increase in the Hcy level is directly related to the activity of the enzyme cystathionine beta-synthase, which is involved in the metabolism of white substance myelin structures. Therefore, hyperhomocysteinemia is direct evidence of the impaired conduction and synergy of nerve impulses between neurons in brain structures..$^{(7)} \mathrm{An}$ increase in the AII level is a direct consequence of hyperhomocysteinemia, which provokes a cytotoxic effect on the vascular endothelium, which in turn potentiates expression of prostacyclin derivatives, and which, through feedback, lead to an even greater spasm of the microcirculation network of CNS. ${ }^{(11)}$

The complexity of pathogenetic mechanisms involving the metabolism of neurobiochemical markers must be taken into account when choosing the optimal theraputic regimen for hypoxic-ischemic brain injury in order to stabilize microcirculation and myelin structures of the brain, and to reduce dysmetabolism and the consequences of the perinatal CNS lesions.

The aim of this study was to evaluate, based on the analysis of neurobiochemical markers, the effectiveness of pathogenetically substantiated therapy for disorders of the psychomotor and physical development of children in the first year of life who underwent perinatal hypoxia.

\section{Materials and Methods}

The study included 419 patients (52\% boys and $48 \%$ girls) aged from 1 to 6 months. The main group included 336 patients in the first year of life who received inpatient treatment for perinatal CNS damage of different degrees of severity. The control group included 83 apparently healthy children $(n=43$ between the ages of 1 to 3 months and $n=40$ between the ages of 4 to 6 months).

Children in the control group passed standard clinical examinations in specified periods of observation at the stage of outpatient services. There were several obligatory criteria for patients to be included in the control group: absence of neurological symptoms, absence of a neurologist's supervision, and pharmacotherapy of neurological deviations during the first year of life.

The main group was divided into two subgroups according to age: Group $1(n=163)$ between the ages of 1 and 3 months and Group $2(n=173)$ between the ages of 4 and 6 months.

It should be noted that the age period of 1-3 months is characterized by a decrease in both neuronal loss and the severity of neurological disorders, which is especially important for the timely diagnosis of ND. In the age period of 4-6 months, there is an aggravation of neurodystrophic processes, a rupture of synaptic connections, and a disruption in the interaction of different areas of the brain. All of which determine a broader clinical picture of neurologic symptoms in this age group.

In accordance with the severity of the CNS lesion, the main group was also divided into 3 subgroups: mild degree $(n=122)$, moderate degree $(n=118)$, and severe degree $(n=96)$.

To assess the risk factors and the dynamics of clinical manifestations of the perinatal CNS damage consequences, we evaluated the women's somatic health, reproductive and gynecological history, and peculiarities of the course and complications of pregnancy and childbirth, using a scale of the optimal course of gestation (SOCG) and a scale of the optimal course of delivery (SOCD). ${ }^{(11)}$ To assess the severity of perinatal CNS damage, the Apgar score at birth was taken into account. ${ }^{(12)}$ The consequences of the perinatal CNS damage according to its severity were established during a neurologic examination and evaluation of the children's neurological status with the subsequent formation of a list of dominant clinical symptoms. ${ }^{(9)}$ The analysis of individual physical development of the children was carried out using $\mathrm{Z}$ scores (weight, age, head circumference) and centiles ( 7 intervals ("corridors")) according to the WHO standard program WHO AnthroPlus, ${ }^{(13)}$ which made it possible to assess the homogeneity of research groups on the studied criteria and markers.

The obtained Z-score data were correlated as follows: $0.672 \leq 0.676$ - "normal" physical development; $-1.28 \leq 0.671$ and $0.677 \leq 1.28$ - physical development "below average" and "above average," respectively; $1.89 \leq-1.29$ and $1.29 \leq 1.89$ -physical development "low" and "high,"; $z \leq-1,9$ and $1,9 \leq z$ - "very low" and "very high" physical development, respectively. ${ }^{(14)}$

The concentrations of biochemical markers in the blood were evaluated in all children at admission and after treatment. The serum level of L-Hcy was determined by EIA using «Axis-Shield» test kit. The serum level of the beta subunit of human NGF (beta-NGF) was measured by EIA (Beta-NGF, 
«RayBio», Russia). S100 protein was evaluated by means of the ELISA method, with the Cobas e411 analyser (Roche Diagnostics GmbH, Germany) and reagents by BioKhimMak (Russia). The serum level of AII was determined by using EIA kits according to manufacturer instructions (BCM Diagnostics, Moscow, Russia).

In accordance with a treatment regimen, the main group was also divided into 2 subgroups: subgroup A $(n=170)$, patients who received therapy depending on a general clinical manifestation (Scheme A); and subgroup B $(n=166)$, patients who received therapy depending on a dominant syndrome and variability of neurobiochemical markers (Scheme B).

During treatment, we used therapeutic agents with various degrees of nootropic effect, vasoactive agents, folic acid, B vitamins. For correction of spasticity, drugs with muscle relaxant effect were used. For correction of increased intracranial pressure, we used diacarb, triampur and magnesium sulfate. Non-drug therapies in all treatment regimens included massage, physical therapy, physiotherapy

The study was approved by the Voronezh State Medical University Ethics Committee (Protocol No. 6 of October 19, 2013). Written informed consent was obtained from the child's parents.

Statistical analysis was performed using StatSoft Statistica v6.0. Multiple comparisons were performed with one-way ANOVA and post-hoc Tukey HSD test. A probability value of $P<0.05$ was considered statistically significant.

\section{Results and Discussion}

In the control group, SOCG was $77 \pm 3 \%$, SOCD - $67 \pm 4 \%$, Apgar score - 7 $\pm 1, \mathrm{Z}$-score - $0 \pm 0.8 \mathrm{CU}$, and ND severity - $29 \pm 1$ points. The parameters of the physical and psychomotor states in children according to the age group and severity of the CNS lesion are presented in Table 1. The analysis showed that the severity of the CNS lesion was reliably associated with the degree of ND, the markers of the optimal course of pregnancy and childbirth, and that the state of the physical development of children reliably reflected the established severity of the CNS lesion (CNSL).

An analysis of the frequency of identified neurologic syndromes showed that, regardless of age, the incidence of neurologic syndromes increased with an increase in the severity of the CNS lesion. It should be noted that in Group 1 , regardless of the degree of severity of the CNS lesion, the syndrome of motor disorders was dominant $(58.4 \%)$ in combination with hyperexcitability syndrome $(47.6 \%)$, to which the syndrome of posthypoxic ventricular dilatation (26.3\%) was added at a severe degree of CNS damage. In Group 2, the syndrome of motor disorders (34.7\%) and the syndrome of delayed psychomotor development (31.9\%) were dominant.

Further, the blood levels of biochemical markers were assessed depending on the severity of the CNS lesion. In Group 1 patients with a mild to moderate degree of CNS damage, the values of the S100 protein significantly increased by $48 \%$ and $86 \%$, respectively, compared to the control level $(175.7 \pm 19.6$ $\mathrm{pg} / \mathrm{ml}$ ). The severe degree of CNS damage was characterized by a decrease in the $\mathrm{S} 100$ protein level by $\approx 33 \%$ without statistical significance. In Group 2, regardless of the degree of severity of the CNS lesion, this marker had a consistently high level: by $42 \%-48 \%$ higher than the norm.

Table 1.

The physical and psychomotor states of the children and the severity of the CNS lesion

\begin{tabular}{|c|c|c|c|c|c|}
\hline 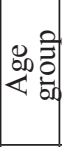 & $\frac{\frac{0}{2}}{\frac{\pi}{\pi}}$ & $\begin{array}{c}\text { Mild } \\
\text { degree } \\
\text { of CNSL } \\
(1)\end{array}$ & $\begin{array}{c}\text { Moderate } \\
\text { degree of } \\
\text { CNSL } \\
(2)\end{array}$ & $\begin{array}{c}\text { Severe } \\
\text { degree of } \\
\text { CNSL } \\
(3)\end{array}$ & Statistics \\
\hline \multirow{6}{*}{ 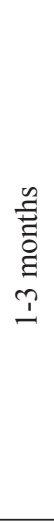 } & $\mathrm{n}$ & 60 & 58 & 45 & \\
\hline & $\begin{array}{l}\mathrm{ND}, \\
\text { points }\end{array}$ & $25 \pm 2$ & $19 \pm 2$ & $12 \pm 1$ & $\begin{array}{l}\mathrm{F}=11.8583 \mathrm{P}=0.0000 \\
\mathrm{P}_{1-2}=0.0453, \mathrm{P}_{1-3}=0.0000 \\
\mathrm{P}_{2-3}=0.0273\end{array}$ \\
\hline & $\begin{array}{l}\text { SOCG, } \\
\%\end{array}$ & $63 \pm 4 \%$ & $51 \pm 6 \%$ & $34 \pm 4 \%$ & $\begin{array}{l}\mathrm{F}=8.3469 \mathrm{P}=0.0004 \\
\mathrm{P}_{1-3}=0.0002 \mathrm{P}_{2-3}=0.0486\end{array}$ \\
\hline & $\begin{array}{l}\text { SOCD, } \\
\%\end{array}$ & $58 \pm 3 \%$ & $44 \pm 3 \%$ & $37 \pm 3 \%$ & $\begin{array}{l}\mathrm{F}=12.3615 \mathrm{P}=0.0000 \\
\mathrm{P}_{1-2}=0.0023, \mathrm{P}_{1-3}=0.0000\end{array}$ \\
\hline & $\begin{array}{l}\text { Apgar } \\
\text { score }\end{array}$ & $6 \pm 1$ & $5 \pm 1$ & $4 \pm 1$ & $\mathrm{~F}=0.9392 \mathrm{P}=0.3931$ \\
\hline & $\begin{array}{l}\text { Z-score, } \\
\mathrm{CU}\end{array}$ & $0.9 \pm 0.2$ & $1.4 \pm 0.1$ & $1.9 \pm 0.1$ & $\begin{array}{l}\mathrm{F}=10.6572 \mathrm{P}=0.0000 \\
\mathrm{P}_{1-2}=0.0392, \mathrm{P}_{1-3}=0.0000\end{array}$ \\
\hline \multirow{6}{*}{ 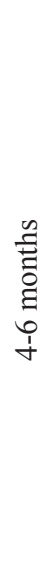 } & n & 62 & 60 & 51 & \\
\hline & \begin{tabular}{|l} 
ND, \\
points
\end{tabular} & $22 \pm 1$ & $17 \pm 2$ & $10 \pm 2$ & $\begin{array}{l}\mathrm{F}=12.1910 \mathrm{P}=0.0000 \\
\mathrm{P}_{1-3}=0.0000 \mathrm{P}_{2-3}=0.0133\end{array}$ \\
\hline & $\begin{array}{l}\text { SOCG, } \\
\%\end{array}$ & $62 \pm 4 \%$ & $50 \pm 3 \%$ & $36 \pm 3 \%$ & $\begin{array}{l}\mathrm{F}=13.9444 \mathrm{P}=0.0000 \\
\mathrm{P}_{1-2}=0.0316, \mathrm{P}_{1-3}=0.0000 \\
\mathrm{P}_{2-3}=0.0147\end{array}$ \\
\hline & $\begin{array}{l}\text { SOCD, } \\
\%\end{array}$ & $57 \pm 2 \%$ & $43 \pm 3 \%$ & $34 \pm 3 \%$ & $\begin{array}{l}\mathrm{F}=18.6146 \mathrm{P}=0.0000 \\
\mathrm{P}_{1-2}=0.0006, \mathrm{P}_{1-3}=0.0000 \\
\mathrm{P}_{2-3}=0.0544\end{array}$ \\
\hline & $\begin{array}{l}\text { Apgar } \\
\text { score }\end{array}$ & $5 \pm 1$ & $5 \pm 1$ & $4 \pm 1$ & $\mathrm{~F}=0.3425 \mathrm{P}=0.7105$ \\
\hline & $\begin{array}{l}\text { Z-score, } \\
\text { CU }\end{array}$ & $1.0 \pm 0.1$ & $1.5 \pm 0.1$ & $2.1 \pm 0.1$ & $\begin{array}{l}\mathrm{F}=29.1534 \mathrm{P}=0.0000 \\
\mathrm{P}_{1-2}=0.0011, \mathrm{P}_{1-3}=0.0000 \\
\mathrm{P}_{2-3}=0.0002\end{array}$ \\
\hline
\end{tabular}

In Group 1, the level of NGF increased by $14 \%$ relative to normal indices at a mild degree of CNS damage, but at moderate and severe degree, this indicator decreased by $10 \%$ and $25 \%$, respectively, compared to the control level. In Group 2 , this marker statistically decreased only at a mild degree of CNS damage.

The level of L-Hcy exceeded the control values in both groups regardless of the degree of severity of the CNS lesion, with a maximum threefold increase in Group 2 patients with a severe degree of the CNS lesion. In Group 1, the AII level exceeded the control values regardless of the degree of severity of the CNS lesion, but in Group 2, it decreased with increasing severity of the CNS lesion.

The levels of the studied markers before the therapeutic interventions did not differ statistically in subgroups A and B. Dynamic changes in the levels of neurobiochemical markers and the degree of ND after treatment are presented in Table 2. 
Table 2.

Dynamic changes in the levels of neurobiochemical markers and the degree of ND after treatment

\begin{tabular}{|c|c|c|c|c|c|c|c|}
\hline \multirow[t]{2}{*}{ Age group } & \multirow[t]{2}{*}{ Variable } & \multicolumn{2}{|c|}{$\begin{array}{c}\text { Mild degree of } \\
\text { CNSL }\end{array}$} & \multicolumn{2}{|c|}{$\begin{array}{c}\text { Moderate degree of } \\
\text { CNSL }\end{array}$} & \multicolumn{2}{|c|}{$\begin{array}{c}\text { Severe degree of } \\
\text { CNSL }\end{array}$} \\
\hline & & Scheme A & Scheme B & Scheme A & Scheme B & Scheme A & Scheme B \\
\hline \multirow{6}{*}{$1-3$ months } & $\mathrm{n}$ & 30 & 29 & 30 & 29 & 24 & 21 \\
\hline & $\begin{array}{l}\text { ND } \\
\text { (score) }\end{array}$ & $24 \pm 1$ & $27 \pm 1^{*}$ & $20 \pm 1$ & $23 \pm 1 *$ & $13 \pm 1$ & $17 \pm 1^{*}$ \\
\hline & $\mathrm{S}-100(\mathrm{pg} / \mathrm{ml})$ & $213.3 \pm 27.6$ & $165.1 \pm 21.4$ & $312.8 \pm 36.9$ & $273.4 \pm 32.3$ & $331.3 \pm 34.2$ & $306.6 \pm 31.7$ \\
\hline & $\mathrm{NGF}(\mathrm{pg} / \mathrm{ml})$ & $24.5 \pm 1.97$ & $27.8 \pm 2.2$ & $16.2 \pm 1.9$ & $18.3 \pm 2.2$ & $11.3 \pm 1.3$ & $11.9 \pm 1.2$ \\
\hline & L-Hcy $(\mu \mathrm{mol} / \mathrm{ml})$ & $7.82 \pm 0.57$ & $5.81 \pm 0.42 *$ & $9.19 \pm 0.76$ & $6.11 \pm 0.43 *$ & $10.7 \pm 0.99$ & $7.96 \pm 0.98$ \\
\hline & AII (ng/ml) & $0.116 \pm 0.017$ & $0.101 \pm 0.019 *$ & $0.134 \pm 0.012$ & $0.122 \pm 0.014$ & $0.134 \pm 0.089$ & $0.12 \pm 0.076$ \\
\hline \multirow{6}{*}{ 4-6 months } & $\mathrm{n}$ & 31 & 32 & 30 & 29 & 25 & 26 \\
\hline & $\begin{array}{c}\text { ND } \\
\text { (score) }\end{array}$ & $21 \pm 1$ & $24 \pm 1 *$ & $16 \pm 1$ & $19 \pm 1^{*}$ & $11 \pm 1$ & $14 \pm 1 *$ \\
\hline & $\mathrm{S}-100(\mathrm{pg} / \mathrm{ml})$ & $299.6 \pm 25.1$ & $267.1 \pm 22.4$ & $281.5 \pm 18.1$ & $260.6 \pm 16.7$ & $178.1 \pm 20.7$ & $165.7 \pm 19.8$ \\
\hline & $\mathrm{NGF}(\mathrm{pg} / \mathrm{ml})$ & $17.9 \pm 2.9$ & $19.8 \pm 3.19$ & $11.1 \pm 1.23$ & $11.4 \pm 1.27$ & $8.1 \pm 1.37$ & $8.6 \pm 1.49$ \\
\hline & L-Hcy $(\mu \mathrm{mol} / \mathrm{ml})$ & $10.9 \pm 1.12$ & $7.13 \pm 0.19 *$ & $15.1 \pm 1.82$ & $8.59 \pm 1.11^{*}$ & $22.9 \pm 2.6$ & $14.9 \pm 1.71 *$ \\
\hline & AII (ng/ml) & $0.132 \pm 0.016$ & $0.125 \pm 0.012$ & $0.139 \pm 0.021$ & $0.114 \pm 0.017$ & $0.11 \pm 0.03$ & $0.086 \pm 0.021$ \\
\hline
\end{tabular}

* $-P<0.05$ (between Scheme A and Scheme B within the group).

We found that Scheme B showed advantages for all studied neurobiochemical markers, with statistical significance for L-Hcy regardless of the age group. These data are potentially important, since there is serious under-recognition of neonatal and childhood stroke associated with elevated total homocysteine. ${ }^{(15-19)}$ The positive dynamics were found in the ND severity against the background of Scheme B regardless of the age group and the degree of severity of the CNS lesion. Thus, the pronounced positive dynamics in the levels of neurotrophic and neurovascular markers of the CNS lesion in all age groups reflects the advantage of pathogenetic therapy. Thus, a pathogenetically grounded approach to the choice of therapy for perinatal CNS damage allows reducing the risks of developing severe consequences in the age dynamics.

\section{Competing interests} interests.

The authors declare that they have no competing

\section{References}

1. Balakireva EA, Krasnorutskaya ON, Kalmykova GV. [Unresolved issues of pediatric neurology]. Scientific bulletins of Belgorod State University. Series: Medicine. Pharmacia. 2014; 28.(24-1):5-7. [Article in Russian].

2. Barashnev YuI. [Hypoxic encephalopathy: hypotheses of the pathogenesis of cerebral disorders and the search for methods of drug therapy]. Rossiyskiy Vestnik Perinatologii Pediatrii. 2002; 1:6-13. [Article in Russian].
3. Krasnorutskaya ON, Ledneva VS. [Clinical and biochemical indices in the diagnosis of developmental disorders of children with consequences of perinatal nervous system damage]. Pediatriia. 2018;97(3):175-9. [Article in Russian]. 4. Afanasyeva NV, Strizhakov AV. [Outcomes of pregnancy and childbirth with fetoplacental insufficiency of various severity]. Problems of Gynecology, Obstetrics and Perinatology. 2004; 3(2):7-13. [Article in Russian].

5. Golosnaia GS. [The role of inhibitors of apoptosis in the diagnosis and prediction of outcomes of perinatal hypoxic brain lesions in newborns]. Pediatria. 2005; 84(3):30-35. [Article in Russian].

6. Krasnorutckaya ON, Balakireva EA, Zu'kova AA, Dobrynina IS. [Assessment of Biochemical Markers of Perinatal Injuries of Central Nervous System in the Children]. Journal of New Medical Technologies. 2014; 21(2):26-29. [Article in Russian].

7. Lobanova LV. Hypoxic lesions of the brain in term infants - causes, pathogenesis, clinical and ultrasound diagnostics, prognosis and tactics of conducting children at an early age. Abstract of ScD Thesis. Ivanovo; 2000. [In Russian].

8. Martinchik AN, Baturin AK, Keshabyats EE, Peskova EV. [Retrospective estimation of anthropometric indicators in Russian children in 1994-2012 according to the new WHO standards]. Journal «Pediatria» named after G.N. Speransky. 2015;1:156-60. [Article in Russian].

9. Petrukhin AS. Neurology of childhood. M., 2004. [In Russian].

10. Esser S, Lampugnani MG, Corada M, Dejana E, Risau W. Vascular endothelial growth factor induces VE-cadherin tyrosine phophorylation in endothelial cells. J Cell Sci. 1998;111(Pt 13):1853-65. 
11. Palchik AB, Shabalov NP. Hypoxic-ischemic encephalopathy of newborns. 2nd ed. M: Medpressinform; 2009. [In Russian].

12. Baturin AK, Keshabyants EE, Martinchik AN, Peskova EV. [Retrospective assessment of anthropometric measurements of children in Russia 1994-2012 according to the new WHO standards]. Pediatriia. 2015; 94(1):156-160. [Article in Russian].

13. WHO growth reference. WHO AnthroPlus software [Electronic resourse]. Available at: http://www.who.int/ growthref/tools/en/.

14. de Onis M, Garza C, Onyango AW, Rolland-Cachera MF; le Comité de nutrition de la Société française de pédiatrie. [WHO growth standards for infants and young children]. Arch Pediatr. 2009;16(1):47-53. doi: 10.1016/j.arcped.2008.10.010. [Article in French].

15. van Beynum 1M, Smeitink JA, den Heijer M, te Poele
Pothoff MT, Blom HJ. Hyperhomocysteinemia: a risk factor for ischemic stroke in children. Circulation. 1999;99(16):2070- 2 16. Nelson R. Neonatal and childhood stroke remain underdiagnosed. Lancet. 2002;360:1306.

17. Cardo E, Vilaseca MA, Campistol J, Artuch R, Colome C, Pineda M. Evaluation of hyperhomocysteinaemia in children with stroke. Eur J Paediatr Neurol 1999;3(3):113-7.

18. Hogeveen M, Blom HJ, Van Amerongen M, Boogmans B, Van Beynum IM, Van De Bor M. Hyperhomocysteinemia as risk factor for ischemic and hemorrhagic stroke in newborn infants. J Pediatr. 2002;141(3):429-31.

19. JoachimE, Goldenberg NA,Bernard TJ,Armstrong-WellsJ, Stabler S, Manco-Johnson MJ. The methylenetetrahydrofolate reductase polymorphism (MTHFR c.677C $>$ T) and elevated plasma homocysteine levels in a U.S. pediatric population with incident thromboembolism. Thromb Res. 2013;132(2):170-4. doi: 10.1016/j.thromres.2013.06.005. 